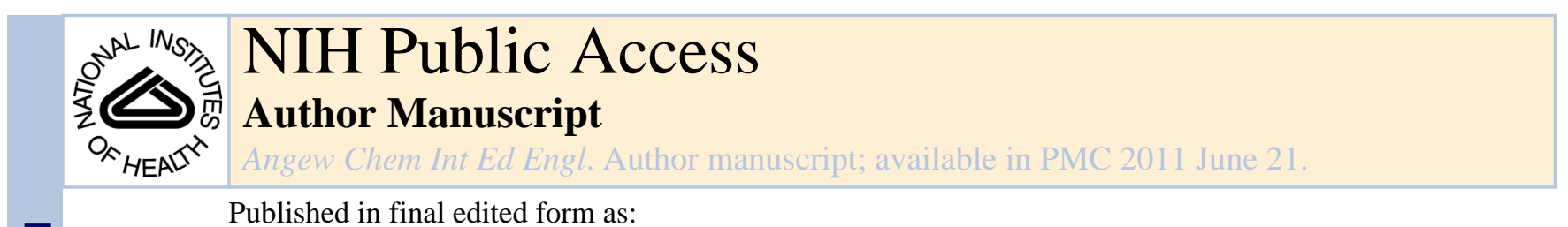

Angew Chem Int Ed Engl. 2010 ; 49(4): 760-762. doi:10.1002/anie.200905632.

\title{
Mechanistic Insights into the Formation of InP Quantum Dots*
}

\author{
Peter M. Allen ${ }^{\dagger}$, Brian J. Walker ${ }^{\dagger}$, and Moungi G. Bawendi \\ Department of Chemistry, Massachusetts Institute of Technology, 77 Massachusetts Ave., Fax: \\ 617 452-2708
}

Moungi G. Bawendi: mgb@mit.edu

\section{Abstract}
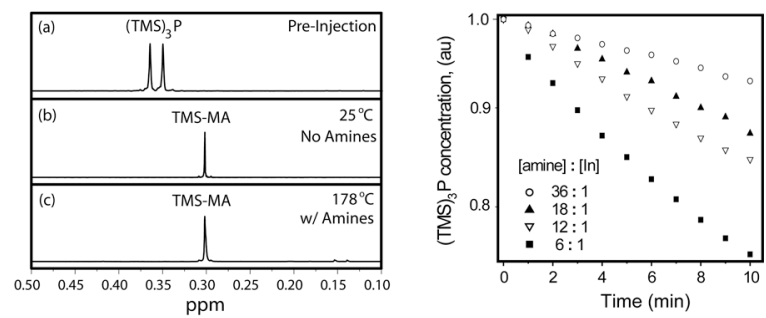

This paper examines the molecular mechanism of InP colloidal quantum dot (QD) syntheses. Unlike methods for monodisperse PbSe and CdSe we found that existing InP syntheses result in total depletion of molecular phosphorous species following nucleation, so QD growth is due exclusively to non-molecular ripening. We find that amines inhibit precursor depletion via solvation, and these findings may lead to better synthetic methodology for InP QDs.

\section{Keywords}

Indium Phosphide; Nanocrystal; Mechanism; Quantum Dot; Nucleation

This paper presents a mechanistic exploration of colloidal III-V InP quantum dot (QD) syntheses. ${ }^{[1-3]}$ InP QDs are of increasing technological interest as a replacement for CdSe QDs in visible light applications. However, the synthetic methodology for InP QDs has not produced QDs with narrow size distributions relative to CdSe and PbSe QDs. ${ }^{[1-5]}$ Studies of the molecular mechanisms involved in the formation of QDs have only recently been reported for II-VI CdSe and IV-VI PbSe QDs. ${ }^{[6,7]}$ As for InP QDs, the molecular mechanisms underlying QD formation are essentially unknown. We investigated the reactions involved in InP QD formation in order to understand the broad size distributions in current InP QD syntheses.

In a simplified view of the formation of monodisperse colloids two general events should occur; (i) an initial nucleation of colloids followed by (ii) subsequent growth of these nuclei from molecular precursors. ${ }^{[8,9]}$ Studies on the growth of CdSe and PbSe QDs have shown

\footnotetext{
** This work was supported in part by the MIT-Harvard NIH CCNE (1U54-CA119349) and the US ARO through the ISN (W911NF-07-D-0004).This work also made use of the DCIF (CHE-980806, DBI-9729592). B.J.W. was supported by a NSF Graduate Research Fellowship. Special thanks to Alejandro Lichtscheidl for helpful discussions on NMR experiments and Jeffrey Simpson for assistance with HMBC measurements.

Correspondence to: Moungi G. Bawendi, mgb@mit . edu.

$\dagger$ These authors contributed equally to this work

Dedicated in Memory of Peter Curtin
} 
these systems fulfill (i) and (ii). ${ }^{[6,7]}$ For InP QDs, we have found that molecular phosphorus precursors are completely depleted following InP nucleation, indicating that subsequent QD growth is due exclusively to ripening from non-molecular InP species. The inability of InP QD syntheses to satisfy (ii), due to depletion of molecular precursors, may explain the broad size distributions of InP QDs relative to CdSe or PbSe QDs.

Colloidal InP QDs are synthesized by the injection of precursors into a hot solution of surfactants, or by mixing precursors at room temperature (RT) followed by heating. ${ }^{[1-3]}$ In these reactions, Indium (III) myristate $\left[\operatorname{In}(\mathrm{MA})_{3}\right]$ reacts with tris(trimethylsilyl) phosphine $\left[(\mathrm{TMS})_{3} \mathrm{P}\right]$ at elevated temperatures to produce TMS-myristate (TMS-MA) and InP QDs (scheme 1, overall). By operating at reduced temperatures, with amines, it is possible to monitor the evolution of molecular species during InP formation. We find amines inhibit precursor decomposition, contrary to previous claims that amines act as 'activating agents' in InP QD synthesis. ${ }^{[2,10-13]}$

We propose a mechanism for amine-inhibited InP QD synthesis in scheme 1. Initially $\operatorname{In}(\mathrm{MA})_{3}$ is coordinated to Lewis base(s), such as octylamine (OA), in the outer (solvation) sphere. In the reversible first step, one [(TMS $\left.)_{3} \mathrm{P}\right]$ becomes incorporated into the solvation sphere (complex 1). 1 then loses a myristate ligand, a stable In-P bond forms, and the coordinated phosphine loses a TMS group, irreversibly forming a molecular intermediate (complex 2). 2 reacts further to form [InP] clusters and nanocrystals. Evidence that supports this mechanism will be described below.

To probe the evolution of molecular species during InP QD synthesis, we used ${ }^{1} \mathrm{H}$ NMR spectroscopy to investigate species with trimethylsilyl (TMS) substituents. In this reaction the TMS group is the only likely ligand for molecular phosphines, so the high ${ }^{1} \mathrm{H}$ NMR sensitivity of the TMS group permits the observation of any P-containing molecules or decomposition products present at significant concentration. Reactions were performed in sealed NMR tubes with $0.02 \mathrm{M} \operatorname{In}(\mathrm{MA})_{3}, 0.01 \mathrm{M}(\mathrm{TMS})_{3} \mathrm{P}, 0.0-1.44 \mathrm{M}$ octylamine, and $0.03 \mathrm{M}$ diphenylmethane as an internal standard, in toluene- $\mathrm{d}_{8}$.

In the absence of octylamine, a ${ }^{1} \mathrm{H}$ NMR spectrum taken within three minutes of mixing In(MA) $)_{3}$ and (TMS $)_{3} \mathrm{P}$ at RT showed quantitative conversion of (TMS $)_{3} \mathrm{P}$ to TMS-MA (Figure 1a-b). The rapid decomposition of (TMS $)_{3} \mathrm{P}$ is due to the direct approach of $(\mathrm{TMS})_{3} \mathrm{P}$ to the In center, circumventing outer sphere equilibria en route to the production of a stable Si-O bond in the TMS-MA product. The exceedingly fast conversion of (TMS) ${ }_{3} \mathrm{P}$ to TMS-MA at RT occurs on a time-scale that is not practical for monodisperse QD synthesis or kinetic analysis by NMR. ${ }^{[6-9]}$

For literature procedures at elevated temperatures containing octylamine, we find no molecular precursors remain shortly after reaction initiation at high temperature. A sealed NMR tube with a composition similar to those previously reported was heated at the published reaction temperature $\left(178{ }^{\circ} \mathrm{C}\right)^{[2]}$ and showed no (TMS $)_{3} \mathrm{P}$ after 1 minute (Figure 1c). Our findings, with and without octylamine, demonstrate that previously reported reaction conditions for InP QDs are based on ripening of non-molecular InP species, similar to those used for InAs, ${ }^{[14]}$ and do not fulfill the requirements for the formation of monodisperse colloids.

However, when octylamine containing $\mathrm{InP}$ reaction mixtures were run at $40{ }^{\circ} \mathrm{C}$, the reaction rate slowed sufficiently to permit kinetic analysis. From time-resolved ${ }^{1} \mathrm{H}$ NMR spectra (Figure 2), four species account for $100 \%$ of all TMS groups. (TMS) ${ }_{3} \mathrm{P}$ and TMS-MA together account for over $90 \%$ of all TMS groups; the remaining TMS groups are either associated with the intermediate 2 (Figure 2a, inset) or the silated octylamine (TMS-OA) that occurs with $<5 \%$ yield under standard conditions. The relative rates of $(\mathrm{TMS})_{3} \mathrm{P}$ 
depletion and of TMS-MA growth are consistent with near quantitative conversion of $(\mathrm{TMS})_{3} \mathrm{P}$ to TMS-MA (Figure $2 \mathrm{~b}$ ). Linear evolution at early times facilitated the analysis of initial rates.

We attribute the doublet at $0.26 \mathrm{ppm}$ to $\mathbf{2}$ as noted above. The doublet is split by $4.4 \mathrm{~Hz}$ (consistent with ${ }^{31} \mathrm{P}-{ }^{1} \mathrm{H}$ 3-bond coupling), ${ }^{[15]}$ which suggests a P-containing species that retains at least one TMS group. We corroborated this assignment with a heteronuclear multiple bond coherence (HMBC) experiment, which showed that ${ }^{1} \mathrm{H}$ resonances of $(\mathrm{TMS})_{3} \mathrm{P}$ and 2 were cross-coupled to respective ${ }^{31} \mathrm{P}$ resonances (Figure S10). The ${ }^{1} \mathrm{H}$ NMR resonance of $\mathbf{2}$ has a line-width comparable to that of molecular (TMS) ${ }_{3} \mathrm{P}$ and TMS-MA noted above, indicating that the species has a distinct molecular structure. Finally, the time evolution of the $\mathbf{2}$ resonance shows the characteristic growth and depletion of a reaction intermediate (Figure S1).

Upon increasing the octylamine concentration from 6:1 to 18:1 the rate of (TMS) ${ }_{3} \mathrm{P}$ depletion continued to decrease (Figure 2c); thus amines inhibit, rather than activate, ${ }^{[2,10-13]}$ InP synthesis. As a change in amine ratio influences the rate even at high concentrations, and as the rates do not have a clear power dependence on octylamine concentration in either this or prior studies, ${ }^{[13]}$ the amine does not have a well-defined stoichiometry during the rate-determining step. At octylamine:In ratios greater than 18:1 we observed a diminishing change in the rate with added amine. The high octylamine content reactions also yielded an increase in the TMS-OA product, complicating kinetic analysis.

We find no evidence for other molecular phosphorus compounds, such as $\mathrm{P}-\mathrm{H}$ containing species. The only resonances in the ${ }^{31} \mathrm{P}$ NMR spectra correspond to (TMS) ${ }_{3} \mathrm{P}$ and 2 (Figure $\mathrm{S} 11)$. When monitoring the depletion of (TMS) ${ }_{3} \mathrm{P}$ at various octylamine concentrations, we observe no doublets in the ${ }^{1} \mathrm{H}$ NMR that would indicate the formation of $\mathrm{P}-\mathrm{H}$ species, so this reaction does not appear to be a significant pathway in the decomposition of (TMS) ${ }_{3} \mathrm{P}$.

To account for the mechanism of amine inhibition we measured the initial reaction rate at various temperatures, and these data are summarized on an Eyring plot (Figure 3). The activation entropy indicates that the reaction proceeds via an ordered transition state, likely from an arrangement of two or more species. The activation enthalpy $\left(\Delta H^{\dagger}=51.9 \pm 1.3 \mathrm{~kJ}\right.$ $\mathrm{mol}^{-}$) is about $10 \mathrm{~kJ} \mathrm{~mol}^{-1}$ less than that measured by Liu et al. for CdSe nanocrystal formation, ${ }^{[7]}$ which is plausible for the highly reactive precursors used during InP QD synthesis. The addition of octylamine may decrease the rate (and increase $\Delta G^{\ddagger}$ ) by stabilizing the enthalpy of precursors (increasing $\Delta H^{\ddagger}$ ), but octylamine may also influence the activation entropy.

The amine inhibition of InP synthesis results from solvation effects during the steps that lead to complex $\mathbf{1}, \mathbf{2}$, or both. As the concentration of a competing Lewis base increases, the sterically-hindered (TMS) ${ }_{3} \mathrm{P}$ is less likely to approach the In center. Thus an increase in amine concentration decreases the formation of $\mathbf{1}$, and the observed saturation behavior may arise from crowding of the $\operatorname{In}(\mathrm{MA})_{3}$ ligand sphere.

The large negative $\Delta S^{\ddagger}=-126 \pm 4 \mathrm{~J} \mathrm{~mol}^{-1} \mathrm{~K}^{-1}$ and the $>10^{3}$-fold decrease in rate upon addition of amines are also consistent with solvation changes during nucleophilic substitution. ${ }^{[16]}$ Strong solvation effects are rarely observed for isopolar transition states (e.g. for pericyclic reactions), so it is unlikely that the route from $\mathbf{1}$ to $\mathbf{2}$ occurs in a single step. A potential step for this reaction is via a $S_{N} 2$ transition state that results in charge dispersion. During charge dispersive $\mathrm{S}_{\mathrm{N}} 2$, charged species react to form uncharged products. Because octylamine can hydrogen bond more strongly with the attacking nucleophiles than with $\mathbf{2}$, an increase in amine concentration hinders the formation of the transition state and decreases the formation of $\mathbf{2}$. 
In conclusion, we find that currently-reported InP QD syntheses are based on non-molecular ripening processes. We demonstrated that amines inhibit precursor decomposition which we rationalize via one or more solvation effects. It is apparent that the challenges in the synthesis of III-V QDs are not due to differences in the bonding between II-VI or IV-VI and III-V semiconductors, but instead result from the depletion of molecular precursors following QD nucleation in current III-V QD syntheses.

\section{Experimental Section}

Reactions were performed in $600 \mathrm{mhz} \mathrm{J}$-Young NMR tubes. Toluene- $\mathrm{d}_{8}, 1,2-$ dichlorobenzene- $\mathrm{d}_{2}$ (C.I.L.), diphenylmethane, octylamine (Fluka), and all reaction solutions were stored over $4 \AA$ molecular sieves prior to use. (TMS) ${ }_{3} \mathrm{P}$ (Strem) was used without further purification and $\operatorname{In}(\mathrm{Myr})_{3}$ was prepared as previously reported. ${ }^{[17]}$ NMR samples were prepared in toluene- $\mathrm{d}_{8}$ by mixing $0.35 \mathrm{ml}$ of $\left[\operatorname{In}(\mathrm{MA})_{3}, 0.04 \mathrm{M}\right)$ ], [diphenylmethane, $0.06 \mathrm{M}$, internal standard], and [octylamine, $0.0-1.44 \mathrm{M}$ ] with $0.35 \mathrm{ml}$ of [(TMS $)_{3} \mathrm{P}, 0.02 \mathrm{M}$ ] in a nitrogen filled glovebox, under minimal lighting, and then immediately transferred into a variable temperature $500 \mathrm{mhz}$ Varian NMR for ${ }^{1} \mathrm{H}$ and ${ }^{31} \mathrm{P}$ analysis. A detailed explanation of the kinetic analysis and additional experimental details can be found in the supporting information.

\section{Supplementary Material}

Refer to Web version on PubMed Central for supplementary material.

\section{References}

1. Battaglia D, Peng X. Nano Letters. 2002; 2:1027.

2. Xie R, Battaglia D, Peng X. J. Am. Chem. Soc. 2007; 129:15432. [PubMed: 18034486]

3. Li L, Reiss P. J. Am. Chem. Soc. 2008; 130:11588. [PubMed: 18686956]

4. Murray CB, Norris DJ, Bawendi MG. J. Am. Chem. Soc. 1993; 115:8706.

5. Peng X, Wickham J, Alivisatos AP. J. Am. Chem. Soc. 1998; 120:5343.

6. Steckel JS, Yen BKH, Oertel DC, Bawendi MG. J. Am. Chem. Soc. 2006; 128:13032. [PubMed: 17017765]

7. Liu H, Owen JS, Alivisatos AP. J. Am. Chem. Soc. 2007; 129:305. [PubMed: 17212409]

8. LaMer VK, Dinegar RH. J. Am. Chem. Soc. 1950; 72:4847.

9. Rempel JY, Bawendi MG, Jensen KF. J. Am. Chem. Soc. 2009; 131:4479. [PubMed: 19275244]

10. Micic OI, Ahrenkiel SP, Nozik AJ. Appl. Phys. Lett. 2001; 78:4022.

11. Protiere M, Reiss P. Chem. Commun. 2007:2417.

12. Xu S, Kumar S, Nann T. J. Am. Chem. Soc. 2006; 128:1054. [PubMed: 16433503]

13. Xie R, Li Z, Peng X. J. Am. Chem. Soc. 2009

14. Xie R, Peng X. Angew. Chem. 2008; 47:7677. [PubMed: 18756560]

15. Brevard, C.; Granger, P. Handbook of High Resolution Multinuclear NMR. New York: Wiley; 1981.

16. Reichart, C. Solvents and Solvent Effects in Organic Chemistry. Weinheim: Wiley; 2003.

17. Wang F, Yu H, Li J, Hang Q, Zemlyanov D, Gibbons PC, Wang, Janes DB, Buhro WE. J. Am. Chem. Soc. 2007; 129:14327. [PubMed: 17967012] 


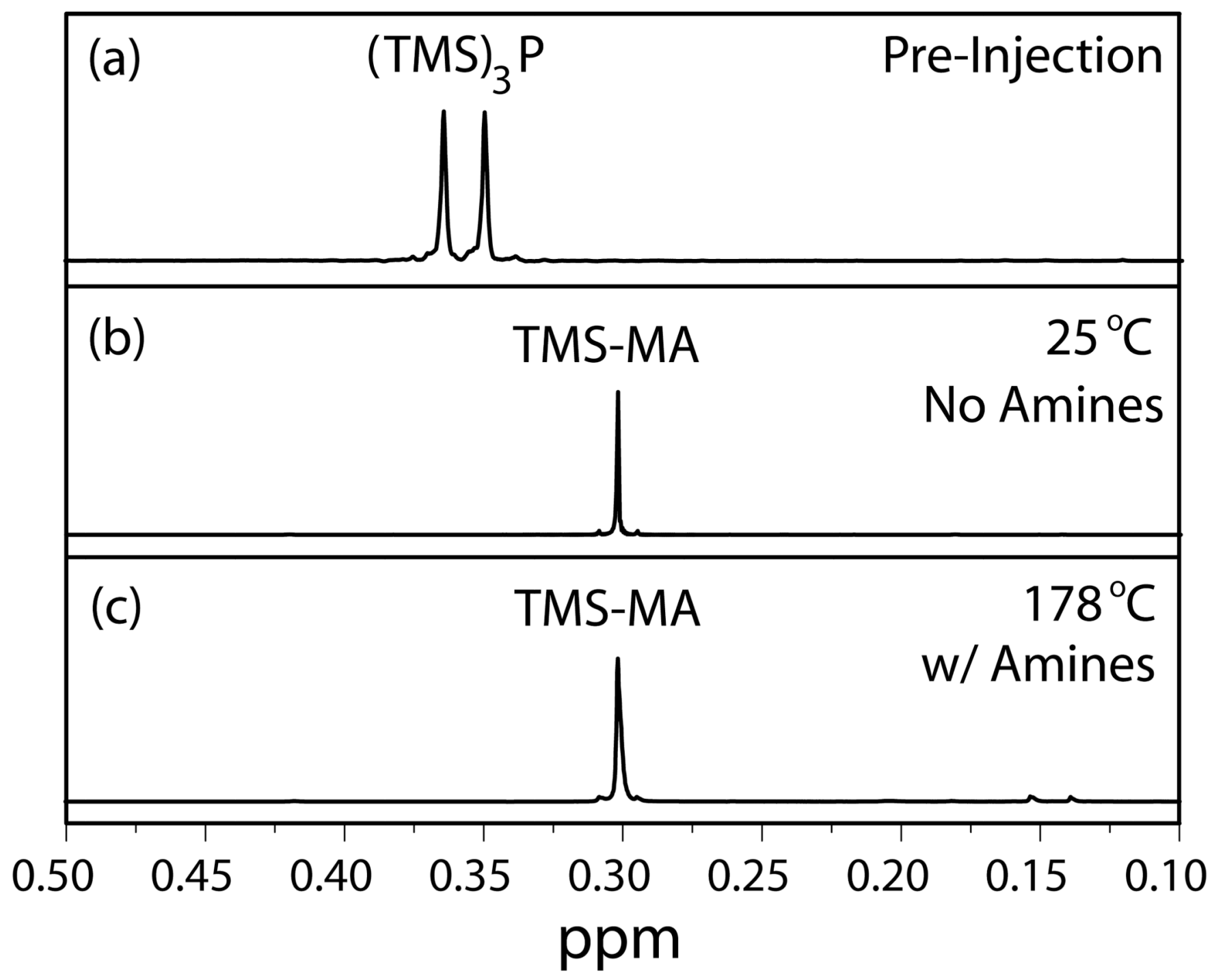

Figure 1.

${ }^{1} \mathrm{H}$ NMR spectra of (a) (TMS) ${ }_{3} \mathrm{P}$ at $20{ }^{\circ} \mathrm{C}$ before injection, (b) reaction mixture of In(MA) 3 and $(\mathrm{TMS})_{3} \mathrm{P}$ in toluene- $\mathrm{d}_{8}$ three minutes after mixing at $25{ }^{\circ} \mathrm{C}$, and (c) reaction mixture of (TMS $)_{3} \mathrm{P}$ and 6:1 octylamine:In(MA) $)_{3}$ in 1,2-dichlorobenzene- $\mathrm{d}_{4}$ after heating at $178{ }^{\circ} \mathrm{C}$ for one minute. Both (b) and (c) demonstrate quantitative conversion of (TMS) ${ }_{3} \mathrm{P}$ to TMS-MA shortly after the reactions are initiated. 

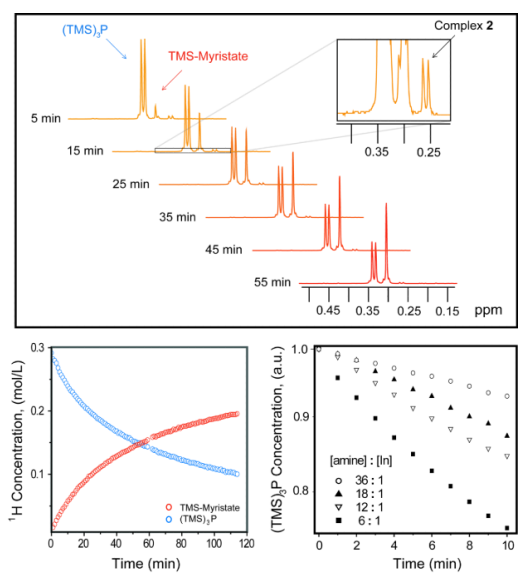

Figure 2.

(a) Time-resolved ${ }^{1} \mathrm{H}$ NMR spectra at $40{ }^{\circ} \mathrm{C}$, showing evolution of (TMS $)_{3} \mathrm{P}$ and TMSmyristate (TMS-MA) resonances during standard conditions for InP QD synthesis with amines. Inset: Detail of 15 -minute ${ }^{1} \mathrm{H}$ NMR spectrum. We assign the doublet at $0.26 \mathrm{ppm}$ to 2. (b) Concentration profiles of (TMS) ${ }_{3} \mathrm{P}$ and TMS-MA protons, determined with 1 min resolution via the integration of spectra represented in figure $2 \mathrm{a}$. (c) Concentration profiles of (TMS) $)_{3} \mathrm{P}$ for InP QD syntheses with varying amine concentrations at $40{ }^{\circ} \mathrm{C}$, normalized at initial time. The reaction rate decreases with increasing amine concentration; reactions without amines reached completion too rapidly to be resolved with our method. 


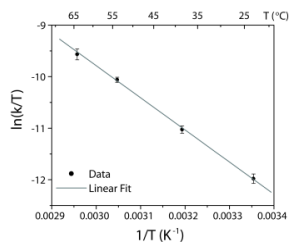

Figure 3.

Eyring plot for amine-based synthesis of colloidal InP QDs, with $\Delta H^{*}=51.9 \pm 1.3 \mathrm{~kJ} \mathrm{~mol}^{-1}$ and $\Delta S^{\ddagger}=-126 \pm 4 \mathrm{~J} \mathrm{~mol}^{-1} \mathrm{~K}^{-1}$. Each point was taken in triplicate, and temperature error was negligible. 


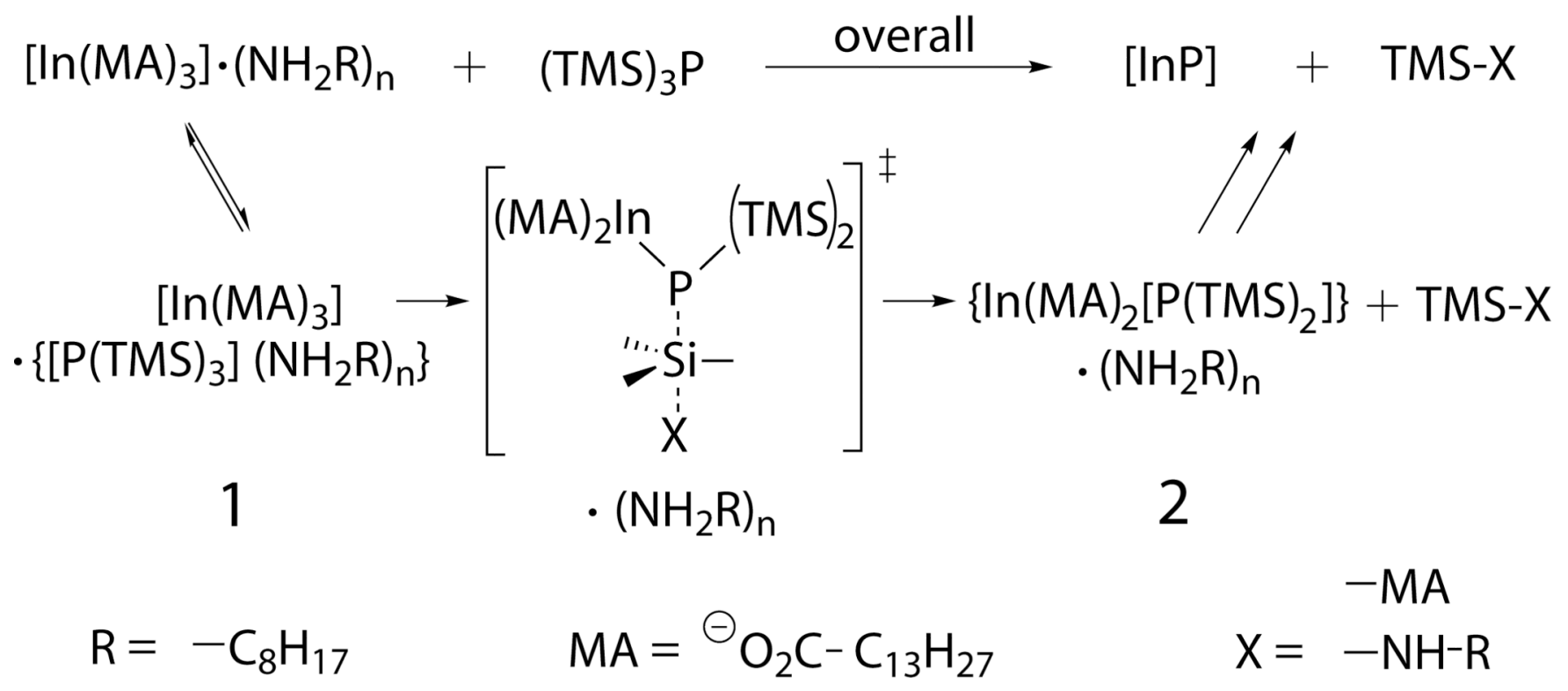

Scheme 1.

Proposed mechanistic pathway for amine-inhibited InP synthesis. Both the formation of outer sphere complex $\mathbf{1}$ and the irreversible formation of intermediate $\mathbf{2}$ are inhibited by increased solvation. Due to the large negative activation entropy and the large rate decrease with added amine, we infer a charge dispersion $\mathrm{S}_{\mathrm{N}} 2$ transition state for TMS-X bond formation and P-TMS bond cleavage. 